\title{
ANÁLISE DA APLICAÇÃO DO ZONEAMENTO AMBIENTAL DA UNIDADE GEOSSISTÊMICA ÁREA DE PROTEÇÃO AMBIENTAL DE SANTA RITA - APASR COMO INSTRUMENTO ESSENCIAL PARA MANEJO ADEQUADO DESSA UNIDADE DE CONSERVAÇÃO
}

\author{
KadjaMonaysa Mendonça de Paula ${ }^{(a)}$, Daniel Nivaldo da Conceição ${ }^{(b)}$ \\ ${ }^{1}$ UFAL/IMA, kay_mmp@hotmail.com \\ ${ }^{2}$ IMA,danieldaconceicao01@gmail.com \\ EIXO: BIOGEOGRAFIA, MANEJO DE ÁREAS NATURAIS E PROTEGIDAS: CONSERVAÇÃO \\ DA BIODIVERSIDADE
}

\begin{abstract}
Resumo:
O presente trabalho tem como finalidade a análise da aplicação do zoneamento ambiental em área de unidade de conservação da natureza, a fim de ressaltar a importância desse instrumento de manejo para a conservação dos recursos naturais e sua consonância com as ações humana.A partir desta análise pôde-se definir a relação entre as principais zonas de ocorrência, ou seja, os principais tipos de uso de solo na área e suas principais ocorrências ambientais.
\end{abstract}

Palavras-chave:Zoneamento; Unidade de Conservação; Área de Proteção Ambiental.

\section{Introdução}

Associar o desenvolvimento social e econômico com a conservação ambiental é um dos grandes desafios do mundo contemporâneo, visto a problemática ambiental promovida por intervenções desordenadas da sociedade sobre a natureza. Por esse motivo, elaborar estudos que auxiliem na proteção de áreas consideradas potenciais naturais é de extrema importância para o meio ambiente.

A criação de unidades de conservação, sejam de proteção integral, onde o objetivo é preservar a natureza sendo admitido apenas o uso indireto de seus recursos naturais, ou de uso sustentável, onde o objetivo baseia-se em compatibilizar a conservação da natureza com o uso sustentável de parte de seus recursos naturais, torna-se a alternativa mais acertada para se obter a conservação dessas áreas com potenciais naturais.

Para que essa conservação ocorra de forma efetiva têm-se como principal instrumento de planejamento e gestão o plano de manejo dessas unidades, que traz como ferramenta norteadora o zoneamento ambiental, responsável por classificar em zonas propensas de uso toda a área da unidade. 
Neste sentido, o presente estudo tem o objetivo de analisar a aplicação do zoneamento ambiental na Área de Proteção Ambiental de Santa Rita, a fim de verificar sua funcionalidade enquanto instrumento de planejamento e gestão em áreas de unidades de conservação Para isso, têm-se como objetivos específicos mapear a delimitação das diferentes zonas ambientais e suas atribuições de usos e atividades compatíveis.

\section{Caracterização da área}

A área em estudo está localizada entre os municípios de Maceió, Marechal Deodoro e Coqueiro Seco, e foi criada como Área de Proteção Ambiental com o objetivo de preservar as características ambientais e naturais das regiões dos canais e lagunas Mundaú e Manguaba.

O território da APA está sob a influência dos climas sub-úmido e úmido, com uma média pluviométrica variando entre 1.700 e $2.300 \mathrm{~mm} / \mathrm{ano}$. Quanto aos recursos hídricos, destacam-se o Complexo Estuarino Lagunar Mundaú-Manguaba (Celmm), composto pelas lagunas Mundaú e Manguaba, interligadas por uma vasta rede de canais interlagunares, formado por ilhas.

O Relevo é constituído pelos Tabuleiros Costeiros, que constituem as falésias fósseis, cobertas pela vegetação típica de mata atlântica nas áreas declivosas e pela Planície Costeira, formada pelos Sedimentos Quaternários de Praia e Aluvião, compondo as áreas de restinga, os alagadiços de mangue, terraços flúvio-lagunares, as praias e cordões arenosos (IMA, 2014).

\section{Metodologia}

Para desenvolvimento deste trabalho foi realizada uma vasta revisão bibliográfica no que referese a temática abordada de unidades de conservação da natureza e seu zoneamento como instrumento de planejamento e gestão.

Além disso, foi gerado, em ambiente GIS, mapa de zoneamento ambiental para posterior analise das zonas de classificação que compõem tal instrumento. Para isso, foi utilizado como base cartográfica a malha municipal do IBGE na escala 1:1.000.000, o mapeamento das regiões hidrográficas do estado de Alagoas na escala de 1:100.000, e ainda o zoneamento contido no plano de manejo da referida área de proteção. Onde foram geradas, em formato polígono, as classes de zoneamento.

Após,foi observada a distribuição das classes de zonas em toda a área em estudo e realizou-se a análise da interferência desse instrumento na gestão da unidade de conservaçãono que tange a sua importância para a proteção dos recursos naturais. 


\section{Resultados}

A PNMA, Lei no 6.938 de 1981, institui o Zoneamento Ambiental, a fim de que este, articulado aos outros instrumentos por ela propostos, contribua na preservação, melhoria e recuperação da qualidade ambiental, bem como no desenvolvimento socioeconômico, na segurança nacional e na proteção à dignidade da vida humana.

Tendo em vista a finalidade desse instrumento observa-se, a partir do mapa gerado de seu zoneamento, a divisão em nove zonas de classificação, zona de ocupação e uso consolidado, zona de ocupação e uso especial, zona de interesse turístico consolidado, zona de interesse turístico especial, zona de recuperação ambiental compensatória, zona de conservação ambiental paisagística, zona de conservação ambiental de transição, zona de recuperação ambiental natural e zona de preservação ambiental.

Essa classificação ocorre em nível de hierarquização que varia desde zonas que contemplam áreas passiveis de uso para atividades humanas como infraestrutura urbano, o que ocorre na zona de ocupação e uso consolidado, a zonas onde é permitido apenas o uso para fins de consolidação da preservação, o que ocorre nas zonas de recuperação ambiental natural.

Percebe-se, a partir da observação do mapa, que a zona dominante nesta unidade de conservação é a zona de preservação ambiental, no entanto, é notória a interferência da zona de ocupação e uso consolidado, influenciando de forma negativa na preservação dos recursos naturais (Figura $1)$. 


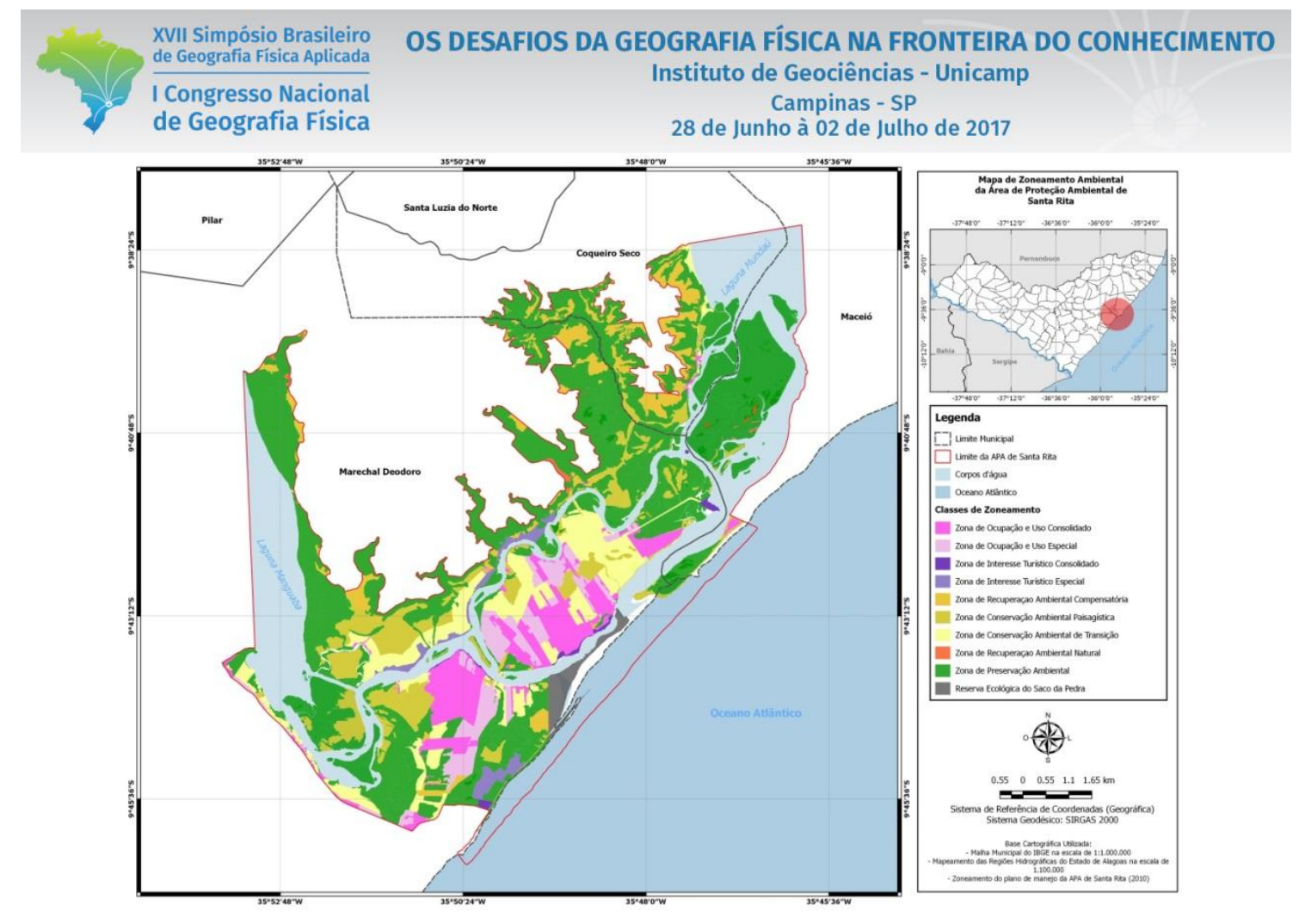

Figura 1 - Mapa de Zoneamento da APA-SR.

\section{Considerações Finais}

A preservação dos recursos naturais e o uso sustentável desses pelo homem é uma preocupação inserida na sociedade nas ultimas décadas, a criação de unidades de conservação e a utilização do zoneamento ambiental como instrumento de gestão apresentam-se como ferramentas eficazes e importantes neste sentido.

Apreende-se com o estudo que não existe área preservada em sua totalidade, mas que pode-se existir um equilíbrio entre o uso consolidado e a preservação em uma mesma unidade paisagística, havendo o que chama-se atualmente de uso sustentável.

\section{Bibliografia}

BRASIL. Ministério do Meio Ambiente. Programa Zoneamento Ecológico-Econômico: diretrizes metodológicas para o Zoneamento Ecológico-econômico do Brasil. Brasília: MMA/SDS, 2001. 109p.

BRASIL. Decreto ${ }^{\circ}$ 4.297, de 10 de julho de 2002. Regulamenta o art. 9o, inciso II, da Lei no 6.938, de 31 de agosto de 1981, estabelecendo critérios para o Zoneamento Ecológico-Econômico do Brasil - ZEE, e dá outras providências. Disponível em: <http:// www.planalto.gov.br/ccivil_03/Decreto/2002/D4297.htm>. Acesso em: 15 mar. 2017.

SOCHAVA, V. B. O estudo de geossistemas. Métodos em questão, n.16, IGUSP. São Paulo, 1977. 51 p. 
